\title{
Applications of Magnetic Water Technology in Farming and Agriculture Development: A Review of Recent Advances
}

\author{
YADOLLAHPOUR ALI ${ }^{1 *}$, RASHIDI SAMANEH ${ }^{1}$ and FATEMEH KAVAKEBIAN ${ }^{2}$
}

\author{
'Department of Medical Physics, School of Medicine, \\ Ahvaz Jundishapur University of Medical Sciences, Golestan Blvd., Ahvaz, Iran. \\ ${ }^{2}$ Department of Anatomical Sciences, Faculty of medicine, \\ Semnan University of Medical Sciences, Semnan, Iran.
}

http://dx.doi.org/10.12944/CWE.9.3.18

(Received: November 24, 2014; Accepted: December 06, 2014)

\begin{abstract}
Magnetic water treatment (MWT) techniques have shown promising potentials in different areas specially agriculture. Safety, compatibility and simplicity, environmentally friendliness, low operating cost and not proven harmful effects are the main advantages of electromagnetic field (EMF) over conventional methods for water treatment. Magnetized or magnetic water (MW) possesses unique physical and chemical characteristics making it a multi-purpose compound with potential benefits in medical treatment, industrial as well as environmental applications. The unique physical and electrochemical characteristics of MW have attracted research interests to develop different devices and techniques in agricultural and environmental applications. Improvements of irrigation water quality and quantity, crop yields and quality, soil improvement and water saving are some of the reported benefits of MWT in agriculture. In addition, magnetic field treatments have shown beneficial effects on the germination of seeds, plant growth and development, the ripening and yield of field crops. The main challenge in applications of MW in agriculture is efficient integrating of irrigation components, designing suitable pumps compatible with technical and field requirements of magnetic MWT systems. The present study reviews the applications of MW in agricultures. The practical challenges in using MW as well as future perspective are discussed.
\end{abstract}

Key words: Magnetic Water Treatment, Agriculture, Magnetized water, Crop yield, Irrigation water treatment.

\section{INTRODUCTION}

Electromagnetic fields (EMFs) have shown great potentials in medical, industrial and environmental applications ${ }^{1-7}$. Because of the electrical origin of the live and existence of all cells and living creatures, EMFs can interact with all living cells so that can modulate their functions. These modulations in appropriate conditions can have useful outcomes such as treatment or inducing the desire characteristics in different compounds. Water is a crucial source for life on the earth. Any living creature needs water to hydrate every cell. Long term and frequent droughts and competing water demands in most parts of the world have caused severe pressure on water resources. In addition, high costs of irrigation in the most countries are the main problem of agriculture development. Annually large quantities of water are used in agriculture. Therefore emerging of new strategies to reduce consumption of water is of significant importance. One of the new strategies is magnetic water technology. Various studies have revealed that magnetic treatment of irrigation water can improve the productivity of water10. MWT has shown promising potential in saving water resources that will be of significant importance in near future. MWT has shown various potentials in environmental and agricultural applications ${ }^{6,3}$. Some of these applications are therapeutic effects of MW, preventing scale deposition, improving irrigation 
water quality and crop yield, scale elimination, soil improvement, corrosion control and wastewater treatment ${ }^{11-13}$.

\section{Magnetic Water Treatment in Agriculture}

In normal or non-MW, the water molecule clusters comprising of many water molecules are loosely attracted. This loose and chaotic form of attraction predisposes the water to toxins and pollutants to travel inside the water molecule cluster. The large structure of these water molecule clusters or presence of toxins blocks large portions of these clusters when they pass through the cell membrane. The smaller size of these chaotic clusters, some of them carrying toxins, can enter the cell with consequent harmful effects ${ }^{11-13}$. Therefore, to hydrate a plant a great deal of normal water is required. Magnetic treatment of water restructures the water molecules into very small clusters, each made up of six symmetrically organized molecules. This tiny and uniform cluster has hexagonal structure thus it can easily enter the passageways in plant and animal cell membranes. In addition, toxic agents cannot enter the MW structure. These features make MW a bio-friendly compound for plant and animal cells. MW can be used to increase crop yield, induce seed germination and benefit the health of livestock. Studies have demonstrated that MW for irrigation can improve water productivity; thus, conserving water supplies for the expected future global water scarcity ${ }^{14}$. In addition, MW is reportedly effective at preventing and removing scale deposits in pipes and water containing structures.

\section{Magnetic Treatment of Irrigation Water}

Previous studies have shown several beneficial effects of MF treatment on the growth of plants. It was demonstrated that an optimal external EMF can increase the rate of the plant growth, especially the percentage of seed germination ${ }^{11,12}$. Podleoeny et al. (2004) reported that exposing the broad bean seeds to variable magnetic strengths during before sowing imposes significant effects on seed germination and seed yield ${ }^{12}$. In addition, they showed that applying MF to broad bean during the growing season can increase the number of pods per plant and reduce the plant losses per unit area. Several studies have demonstrated the effectiveness of MFs on the root growth of various plants $^{14-18}$. Similarly, Muraji et al. (1992) observed that MF treatment increases the root growth of maize ${ }^{18}$. Turker et al (2007) reported that static MF has an inhibitory effect on the root dry weight of maize plants, but had a beneficial effect on root dry weight of sunflower plants [19]. Different studies have shown the inhibitory effect of weak MF on the growth rate of primary roots during early growth ${ }^{16}$, 19. It was demonstrated that MF can decrease the proliferative activity and cell reproduction in meristem cells in plant roots ${ }^{16}$.

Magnetic treated water undergoes several changes in its physical properties. It also exerts several effects on the soil-water-plant system. Leaching the soil with MW significantly increases available soil phosphorus content compared with the leaching with normal water at all soil depths. Behavior of nutrients under an MF is a function of their magnetic susceptibility.

The previous studies have shown that the effects of magnetic treatment varied with plant type and the type of irrigation water used, and there were statistically significant increases in plant yield and water productivity ( $\mathrm{kg}$ of fresh or dry produce per $\mathrm{kL}$ of water used). In particular, the magnetic treatment of recycled water and $3000 \mathrm{ppm}$ saline water respectively increased celery yield by $12 \%$ and $23 \%$ and water productivity by $12 \%$ and $24 \%$. For snow peas, there were $7.8 \%, 5.9 \%$ and $6.0 \%$ increases in pod yield with magnetically treated potable water, recycled water and 1000 ppm saline water, respectively.

\section{Effects on Quality of Water}

Several studies demonstrated that MWT influences molecular and physicochemical properties of water that alter the quality of water ${ }^{20}$. The origin of physical and chemical modulations of water molecules under magnetic treatment is the alteration of water nucleus ${ }^{20-23}$. The effects of magnetic treatment on irrigation water include increasing the number of crystallization centers and the altering the free gas content ${ }^{24}$. Both effects improve the quality of irrigation water. The important components for effective magnetic treatment are flow rate through the apparatus and certain chemical parameters of water, namely, carbonate water hardness of more than $50 \mathrm{mg} / \mathrm{L}$ and concentration of hydrogenous ions in water at $\mathrm{pH}>7$.2. Irrigation with magnetically 
treated water is the most effective for soils with high soda content ${ }^{24}$.

Effects of low level magnetic and EMFs, below $100 \mathrm{mG}$ for AC MF, and below $1000 \mathrm{G}$ for static MF, on purified water include modulating $\mathrm{pH}$ and oxidation"reduction potential (ORP) values ${ }^{25}$. To accurately evaluate the effects of weak MFs on water, subtle experimental conditions such as differential field conditions produced by common lab devices and procedures, and background lab fields, cannot be ignored. Moreover, extending measurements beyond several hours may be essential to reliably observe the presence or absence of these effects ${ }^{25}$.

Experimental studies have shown that magnetic treatment can increase the number of crystallization and modulates the free gas content of the solution ${ }^{25}$. Magnetic treatment on water plays important roles in different procedures influencing a crystallization process such as association, dissociation and nucleation rates ${ }^{26,24,27 .}$

\section{Effects on Crop Yield}

In the field of crop yield, researchers have focused on using of physical growth stimulation approach because of no known adverse effect on the environment. MW technology is a promising physical growth stimulation approach. The characteristics of water treated by the magnetic field can be altered to cause changes in plant properties, growth and production ${ }^{28,29}$. MW can be used for saving irrigation water ${ }^{30}$.

MWT can increase the seed germination ${ }^{31}$. Irrigation with MW modulates several parameters that are associated with the crop yield: growth characteristics, potassium, GA3, kinetin, nucleic acids (RNA and DNA), photosynthetic pigments (chlorophyll a \& b and carotenoids), photosynthetic activity and translocation efficiency of photoassimilates $^{32-36}$. Several studies have shown the enhancement of water productivity in both crop and livestock production, number of flowers and total yield of fruits for different crops including strawberry and tomatoes ${ }^{28,29}$.

In addition, weak MF decreases the speed of cell cycle in meristem cells in plant roots due to the expansion of $\mathrm{G} 1$ phase and sometimes G2 phase. Therefore, the functional activity of genome before replication phase is decreased. Under these mechanisms, weak MF treatments result in the intensification of protein synthesis and disintegration in plant roots ${ }^{16}$. Irrigation with $\mathrm{MW}$ can improve the quality of crops including tomato, broad bean, cress and potato ${ }^{14,35}$

Weak MF can increase the size and volume of mitochondria, calcium over-saturation in cytoplasm and disruptions in different metabolic systems including Ca2+ homeostasis in root cells ${ }^{15}$, ${ }^{16}$. One of the important function of MF treatment is reducing the heat stress effects in different seedlings including cress $^{37}$.

Several studies have revealed beneficial effects of MF treatment in fruit yield and plant growth. Lin and Yotvat (1990) explained that applying magnetically treated water increases productivity of water in both crop and livestock production ${ }^{38}$. Similarly, several studies have shown that MF treatments enhance the flowers and total fruit yield of strawberry and tomatoes ${ }^{28,29}$. Duarte Diaz et al (1997) observed that magnetic treatment increases the nutrients absorption in tomato10. Some of the main effects of magnetic treatment of seeds or irrigation with $\mathrm{MW}$ in plants include plant growth rate, transplant dry weight, transplant leaf area, and seed germination.

\section{Effects on Plant Growth}

Using MW for irrigation of squash increases the weight of squash. Bio-magnetic water is more solvent and has a lower surface tension; therefore, nutrients are absorbed greater in the water28, 39, 40 . MW is the water which are treated with magnetic field or pass through a magnetic device. When water is magnetized, some properties changed which can alter the characteristics of plant, growth and production. It was suggested that MW irrigation could increase the germination of seed ${ }^{41}$. Similarly, other field studies have indicated a significant role of MW irrigation of seeds in improving the growth of seedling ${ }^{35}$, 39. Furthermore, MW improves quantity and quality of bean crop and germination, fresh weight, and shoot length of maize ${ }^{42}$. In addition, magnetic treatment before sowing increases the number of pods per plant and decreased plant losses 
per unit area ${ }^{12}$. The root growth of various plant species can be enhanced using MWT technique ${ }^{15-19}$. Muraji et al reported that the roots of maize plants have the highest growth rate under an MF of $5 \mathrm{mT}$ at $10 \mathrm{~Hz}^{17}$. Moreover, MFs have an important influence on root dry weight of sunflower plants ${ }^{16,19}$.

\section{Effects on Transplant Dry Weight}

The results of a study conducted by ElYazied et al (2011) revealed that applying magnetic seed treatment and/or irrigated with MW in different seasons significantly increases the transplant dry weight compared with the non-treated treatment ${ }^{43}$. In consistent with these results, Gurusamy and Kalavathi (1998) demonstrated that the dry weight of seedling grown from magnetically treated seeds is significantly higher than the untreated cowpea ${ }^{44}$. Ozdemir et al. (2005) reported that electromagnetic treated water enhances the root dry weight by $11 \%$ compared with the control group ${ }^{45}$. Furthermore, Fernandez et al (1996) revealed that the MW irrigation significantly increases the weight of seedling ${ }^{46}$.

\section{Effects on Transplant Leaf Area}

El-Yazied et al (2011) showed that irrigation with MW enhances the leaf area in the grown seedling ${ }^{43}$. Similarly, several other studies have reported improvements of the leaf size of different seedlings grown by magnetically treated seeds ${ }^{47,48}$, 49 .

In this regard, it was found that magnetically water irrigation is an ecological and harmless technology. Therefore, it must be recommended for agriculture applications ${ }^{43}$. Carbonell et al (2004) revealed that the MW increases the contents of various minerals compounds of soil such as nitrogen, phosphorus and potassium and improved the fertilizers dissolve in the soil irrigated with $\mathrm{MW}^{50}$.Various studies have demonstrated higher absorption of nutrients was greater increased if irrigation with magnetically treated water was used ${ }^{10}$, 49. Although it was proved that MF could improve the water attributes but its mechanisms are not well known yet ${ }^{43}$.

In addition, Selim (2002-2005) showed that irrigation of lentil plant with magnetic treated water enhances various crop yields such as number of brunches and pods per plant and weight of pods, etc. Furthermore, they reported improvements of other characteristics such as the height of plant, fresh and dry weight of MW irrigation compared with the tap water irrigation ${ }^{51}$.

\section{Effects on Seed Germination}

An optimal external EMF can influence the speed and percentage of germination ${ }^{11,12}$. The strength of MF and exposure time are among the most significant factors influencing the seed germination, emergence rate and seed yield. Magnetic treatment can accelerate the plant emergence to 2-3 days, compared with the control plants. El-Yazied et al (2011) and Aladjadjiyan (2002) showed that the MF dose and the duration of exposure can affect the germination traits of different seesd including tomato and broad been. They demonstrated that strength of MF plays a significant role on germination percentage ${ }^{42,43}$. In agreement with these results, Souza et al (1999) concluded that best germination percentage of tomato seeds is obtained under the MF strength of 0.1 Tesla with exposure time of 10 minute ${ }^{43,52}$. Several studies have shown that MF strength has significant effects on germination percentage through reducing water salinity ${ }^{51}$. Rochalska (2001) revealed that MF treatment improved the germination process under stress conditions ${ }^{53}$. El-Yazied et al (2011) demonstrated that MF exposure time can significantly influence germination percentage through modulating water salinity. They also concluded that increasing the MF strength significantly reduces the number of days needed for germination as compared with untreated seeds ${ }^{43}$. In line with these findings, Pietruszewski (1999) revealed that wheat seeds treated by MF can speed up germination compared with the untreated samples ${ }^{54}$. Furthermore, exposure time to MF plays a significant role on the germination rate where different exposure periods result in different minimum time required for germination. However, Florez et al (2007) showed that the time needed for germination in each magnetic treatment of various strengths and periods are lower than values recorded by control ${ }^{13}$.

Increasing the salinity level increases the time required for germination. Some studies have reported that increasing the salt concentration delays the tomato seeds germination ${ }^{14,40,55}$. 


\section{Effects on Soil}

Magnetic treatment has reportedly shown various benefits to soil which can improve the water consumption, crop yields and plant growth. The three main functions of magnetic treated water in soil are removal of excess soluble salts, lowering $\mathrm{pH}$ values of soil layers, and dissolving slightly soluble components such as phosphates carbonates and sulfates $^{28,40,56}$. Furthermore, magnetic treated water increases nutrient mobility in soil and enhances extraction and uptake of $\mathrm{P}, \mathrm{K}, \mathrm{N}$ and Fe by plants. Magnetic treated water increases the efficiency of added fertilizers ${ }^{57}$. Magnetic treatment of water increases the water absorption in soil. Furthermore, magnetic treatment of saline irrigation water is reportedly an effective method for soil desalinization. Water treatment by MF decreases the hydration of salt ions and colloids that increases the salt solubility, accelerated coagulation and salt crystallization ${ }^{56}$. The study showed that MW increased leaching of excess soluble salts, lowered soil alkalinity and dissolved slightly soluble salts ${ }^{56}$. Leaching the soil with MW significantly increases available soil phosphorus content compared with the leaching with normal water at all soil depths. Behavior of nutrients under an MF is a function of their magnetic susceptibility.

The increase in salt concentrations reduces final germination percentage. The reduction is significant particularly for high levels of salt concentration (higher than 5000 ppm). Similar results were found by other research groups who found that increasing salt concentration up to $2500 \mathrm{ppm}$ significantly reduced tomato seed germination ${ }^{55,57}$.

\section{Scale Prevention and Elimination}

Suspended particles or solids in water can cause serious problems in irrigation distribution systems and also drink water networks. The deposition of scale can even completely block an irrigation system. Deposition of scale due to entrapped oxygen increases corrosion. When the surface of any pipeline or water-using systems becomes scaled, this insulating scale reduces the efficiency of the system, increases fuel requirements and maintenance ${ }^{58-61}$.

Therefore, there is an ever increasing demand for effectively scale prevention/elimination technique, not only economically, but to insure the minimum environmental pollution attainable. One of the most important applications of $\mathrm{MW}$ is scale prevention and elimination ${ }^{62}$. An effective water treatment program can provide substantial savings in both production time and $\operatorname{costs}^{61,26}$.

MWT directly affects the equilibrium of carbonate in water where induces formation of calcium carbonate particles within a solution. These particles cannot precipitate on pipe walls and other equipment and are transferred to the downstream of pipe flow which can be removed by filtration ${ }^{24,27}$. It was found that using MW can reduce the mineralized coatings inside pipes ${ }^{38}$. Barrett and Parsons (1998) investigated the effect of MW on calcium carbonate (CaCO3) by suppressing nucleation and increasing the rate of crystal growth, and they observed scale reduction ${ }^{63}$. The hexagonally structured of $\mathrm{MW}$ molecule cluster won't allow the bonding of minerals to it and removes scaling from pipes and won't allow new scaling to take effect ${ }^{23,27,59,61,64,65}$.

Gehr et al. (1995) reported that magnetic treatment induces precipitation of gypsum crystals (CaSO4 2H2O) in the solution ${ }^{22}$. They also reported that magnetic treatment may be a useful treatment for scale prevention so that it can decrease the precipitation on solid surfaces and facilitate crystallization $^{22}$. Furthermore, it was demonstrated that applying MF can decrease the $\mathrm{pH}$ of solution and that this change in $\mathrm{pH}$ directly affects the scale growth $^{61,26,24,27,65}$.

To applying MWT for prevention of scale, water must pass through a strong magnet installed on or in a feed line. Afterward, when the water is heated, it has lost its tendency to precipitate scale onto the hot surfaces and the built deposits gain a looser texture that is easily removable ${ }^{66,26},{ }^{24,26,27}$. . In this regard, Parsons et al. (1997) reported that using MWT decreases scale by $48 \%$ and Busch (1997) proposed a $22 \%$ reduction ${ }^{61,65}$. The magnetic device can inhibit the scales growth and remove them at the water line in the pool by $50 \%{ }^{67}$. Reducing and preventing the scale from irrigation water systems can reduce the water consumption up to $30 \%$.

Although MWT is very useful for scale reduction, the exact mechanics of interaction 
between magnetic treatments and calcium carbonate in solution is still unknown. To shed light on the exact mechanism of actions of MWT in exerting physical and electrochemical effects conducting further controlled laboratory and field studies are necessary. In this regard, few studies have been conducted on the effects of magnetic treatment of irrigation water on plant growth and crop and water productivity.

\section{Technical considerations}

A typical MWT system is a simple flange installed on the main pipeline and contains powerful, specific magnetic inductions that restructure the water and minerals passing through them. Most of the devices are in-line invasive and non-invasive as opposed to side-stream. The invasive devices require a section of pipe to be removed and replaced with the device. Most of the invasive devices are larger in diameter than the section of pipe they replace. The increased diameter is partially a function of the magnetic or electromagnetic elements, and also a function of the cross sectional flow area. The flow area through the devices is generally equivalent to the flow area of the section of pipe removed.

The non-invasive in-line devices are designed to be wrapped around the pipe. Therefore, downtime, or line out-of-service time, is minimized or eliminated. In MWT, when irrigation water passes under an MF, it gains a magnetic moment that persists for 24 to $48 \mathrm{hrs}$. Magnetic treatment of irrigation water depends on MF intensity, composition of dissolved salts and velocity of crossing a magnetron of 0.5 inch diameter [61] [26] [24, 27].

\section{CONCLUSION}

MWT has opened new research avenues in agriculture. Safety, compatibility and simplicity, environmentally friendliness, low operating cost and not proven harmful effects are the main advantages of this technique. Improvements of irrigation water quality and quantity, crop yields and quality, soil improvement, scale prevention/elimination in waterusing systems, and water saving are some of the reported benefits of MWT in agriculture. In addition, MF treatments have shown beneficial effects on the germination of seeds, plant growth and development, the ripening and yield of field crops. The main challenge in applications of $\mathrm{MW}$ in agriculture is efficient integrating of irrigation components, designing suitable pumps compatible with technical and field requirements of magnetic MWT systems. To shed light on the exact mechanism of actions of MWT in exerting physical and electrochemical effects conducting further controlled laboratory and field studies are necessary. In this regard, few studies have been conducted on the effects of magnetic treatment of irrigation water on plant growth and crop and water productivity. In addition, further field and laboratory experiments are needed to overcome the field challenges and to gain knowledge about the mechanism of action of the MWT.

\section{REFERENCES}

1. Yadollahpour, A., et al., Repetitive transcranial magnetic stimulation decreases the kindling induced synaptic potentiation: effects of frequency and coil shape. Epilepsy Res, 108(2): p. 190-201 (2014).

2. Yadollahpour, A. and M. Jalilifar, Electromagnetic Fields in the Treatment of Wound:A Review of Current Techniques and Future Perspective. J Pure Appl Microbio, 8(4): 2863-2877 (2014).

3. Yadollahpour, A., M. Jalilifar, and S. Rashidi, Antimicrobial Effects of Electromagnetic Fields: A Review of Current Techniques and Mechanisms of Action. J Pure Appl Microbio,
8(5): p. 4031-4043 (2014).

4. Yadollahpour, A. and S. Rashidi, Therapeutic Applications of Electromagnetic Fields in Musculoskeletal Disorders: A Review of Current Techniques and Mechanisms of Action. Biomedical and Pharmacology Journal, 7(1): p. 23-32 (2014).

5. Yadollahpour, A. and S. Rashidi, A Review of Electromagnetic Field Based Treatments for Different Bone Fractures. Biosci., Biotech. Res. Asia, 11(2): p. 611-620 (2014).

6. Yadollahpour, A., et al., Electromagnetic Fields for the Treatments of Wastewater: A Review of Applications and Future Opportunities. J Pure 
Appl Microbio, 8(5): p. 3711-3719 (2014).

7. Yadollahpour, A. and Z. Rezaee, Electroporation as a New Cancer Treatment Technique: A Review on the Mechanisms of Action. Biomedical \& Pharmacology Journal, 7(1): p. 53-62 (2014).

8. Gholizadeh, M. and H. Arabshahi, The effect of magnetic water on growth and quality improvement of poultry. Middle-East Journal of Scientific Research, 3 (2008).

9. Plantje, M.M.M.J.N., The Effects Of Magnet Treated Irrigation Water On Kentucky Bluegrass In A Greenhouse Environment.

10. Duarte Diaz, C., et al., Effects of magnetic treatment of irrigation water on the tomato crop. Hortic. Abst, 69: p. 494 (1997).

11. Amaya, J., et al., Effects of stationary magnetic fields on germination and growth of seeds. Hortic. Abst, 68: p. 1363 (1996).

12. Podleoeny, J., S. Pietruszewski, and A. Podleoena, Efficiency of the magnetic treatment of broad bean seeds cultivated under experimental plot conditions. Int. Agrophys, 18: p. 65-71 (2004)

13. Flórez, M., M.V. Carbonell, and E. Martínez, Exposure of maize seeds to stationary magnetic fields: Effects on germination and early growth. Environmental and Experimental Botany, 59(1): p. 68-75 (2007).

14. Cuartero, J. and R. Fernández-Muñoz, Tomato and salinity. Scientia Horticulturae, 78(1): p. 83-125 (1998).

15. Belyavskaya, N., Ultrastructure and calcium balance in meristem cells of pea roots exposed to extremely low magnetic fields. Advances in Space Research, 28(4): p. 645650 (2001).

16. Belyavskaya, N., Biological effects due to weak magnetic field on plants. Advances in space Research, 34(7): p. 1566-1574 (2004).

17. Muraji, M., T. Asai, and W. Tatebe, Primary root growth rate of $<$ i $>$ Zea mays $<$ /i $>$ seedlings grown in an alternating magnetic field of different frequencies. Bioelectrochemistry and Bioenergetics, 44(2): p. 271-273 (1998).

18. Muraji, M., et al., Effect of alternating magnetic field on the growth of the primary root of corn. Magnetics, IEEE Transactions on, 28(4): p. 1996-2000 (1992).
19. Turker, M., et al., The effects of an artificial and static magnetic field on plant growth, chlorophyll and phytohormone levels in maize and sunflower plants. Phyton, 46(2): p. 271284 (2007).

20. Cai, R., et al., The effects of magnetic fields on water molecular hydrogen bonds. Journal of Molecular Structure, 938(1): p. 15-19 (2009).

21. Coey, J. and S. Cass, Magnetic water treatment. Journal of Magnetism and Magnetic Materials, 209(1): p. 71-74 (2000).

22. Gehr, R., et al., Reduction of soluble mineral concentrations in $\mathrm{CaSO}<\mathrm{sub}>4</$ sub $>$ saturated water using a magnetic field. Water Research, 29(3): p. 933-940 (1995).

23. Hasson, D. and D. Bramson, Effectiveness of magnetic water treatment in suppressing calcium carbonate scale deposition. Industrial \& Engineering Chemistry Process Design and Development, 24(3): p. 588-592 (1985).

24. Bogatin, J., et al., Magnetic treatment of irrigation water: experimental results and application conditions. Environmental science \& technology, 33(8): p. 1280-1285 (1999).

25. Yamashita, M., C. Duffield, and W.A. Tiller, Direct current magnetic field and electromagnetic field effects on the $\mathrm{pH}$ and oxidation-reduction potential equilibration rates of water. 1. Purified water. Langmuir, 19(17): p. 6851-6856 (2003).

26. Wang, Y., et al., Rapid onset of calcium carbonate crystallization under the influence of a magnetic field. Water Research, 31(2): p. 346-350 (1997).

27. Kozic, V. and L. Lipus, Magnetic water treatment for a less tenacious scale. Journal of chemical information and computer sciences, 43(6): p. 1815-1819 (2003).

28. E-itken, A. and M. Turan, Alternating magnetic field effects on yield and plant nutrient element composition of strawberry (Fragaria $\mathrm{x}$ ananassa cv. Camarosa). Acta Agriculturae Scandinavica, Section B-Soil \& Plant Science, 54(3): p. 135-139 (2004).

29. Danilov, V., et al. Artificial magnetic field effect on yield and quality of tomatoes. in II Symposium on Protected Cultivation of Solanacea in Mild Winter Climates 366. (1993). 
30. Mostafazadeh-Fard, B., et al., Effects of magnetized water and irrigation water salinity on soil moisture distribution in trickle irrigation. Journal of Irrigation and Drainage Engineering, 137(6): p. 398-402 (2010).

31. Ijaz, B., et al., Changes in germination behavior of wheat seeds exposed to magnetic field and magnetically structured water. African Journal of Biotechnology, 11(15): p. 3575-3585 (2014).

32. Moussa, H.R., The impact of magnetic water application for improving common bean (Phaseolus vulgaris L.) production. New York Sci J, 4: p. 15-20 (2011).

33. Vashisth, A. and S. Nagarajan, Effect on germination and early growth characteristics in sunflower ( $<$ i $>$ Helianthus annuus $<$ ) i>) seeds exposed to static magnetic field. Journal of plant physiology, 167(2): p. 149-156 (2010).

34. Kronenberg, K.J., Experimental evidence for effects of magnetic fields on moving water. Magnetics; 21(5): p. 2059-2061 (1985).

35. Maheshwari, B.L. and H.S. Grewal, Magnetic treatment of irrigation water: Its effects on vegetable crop yield and water productivity. Agricultural water management, 96(8): p. 1229-1236 (2009).

36. Pittman, U., Effects of magnetic seed treatment on yields of barley, wheat, and oats in southern Alberta. Canadian Journal of Plant Science, 57(1): p. 37-45 (1977).

37. Ruzic, R. and I. Jerman, Weak magnetic field decreases heat stress in cress seedlings. Electromagnetic Biology and Medicine, 21(1): p. $69-80$ (2002).

38. Lin, I. and J. Yotvat, Exposure of irrigation and drinking water to a magnetic field with controlled power and direction. Journal of magnetism and magnetic materials, 83(1): p. 525-526 (1990).

39. Grewal, H.S. and B.L. Maheshwari, Magnetic treatment of irrigation water and snow pea and chickpea seeds enhances early growth and nutrient contents of seedlings. Bioelectromagnetics, 32(1): p. 58-65 (2011).

40. Mohamed, A.I. And B.M. Ebead, Effect Of Magnetic Treated Irrigation Water On Salt Removal From A Sandy Soil And On The Availability Of Certain Nutrients. International
Journal of Engineering, 2(2): p. 2305-8269 (2013).

41. Aladjadjiyan, A., Physical Factors for Plant Growth Stimulation Improve Food Quality. Food Production-Approaches, Challenges and Tasks, Publisher InTech, p. 145-168 (2012).

42. Aladjadjiyan, A., Study of the influence of magnetic field on some biological characteristics of Zea mais. Journal of Central European Agriculture, 3(2) (2002).

43. Abou El-Yazied, A. and O. Shalaby, SM Khalf and A. El-Satar. Effect of Magnetic Field on Seed Germination and Transplant Growth of Tomato. Journal of American Science, 7(12): p. 306-312 (2011).

44. Gurusamy, C. and D. Kalavathi, Impact of magnetobiology on cowpea (Vigna unguiculata) seeds. Legume Research, 1998. 21(2): p. 117-120.

45. Ozdemir, S., O.H. Dede, and G. Koseoglu, Electromagnetic water treatment and water quality effect on germination, rooting and plant growth on flower. Asian Journal of Water, Environment and Pollution, 2(2): p. 9-13 (2005).

46. Alvarez, M., et al., Biofertilizers And Plant Nutrition. Cultivos tropicales: CT, 17(2): p. 5-8 (1996).

47. Novitsky, Y.I., et al., Growth of green onions in a weak permanent magnetic field. Russian Journal of Plant Physiology, 48(6): p. 709-716 (2001).

48. De Souza, A., et al., Pre-sowing magnetic treatment of tomato seeds: effects on the growth and yield of plants cultivated late in the season. Spanish Journal of Agricultural Research, 3(1): p. 113-122 (2005).

49. Khattab, M., et al., Pre treatments of gladiolus cormels to produce commercial yield: I-effects of GA3, seawater and magnetic system on the growth and corms production. Alexandria Journal of Agricultural Research, 45(3): p. 181-199 (2000).

50. Carbonell, M., et al., Influence of magnetically treated water on germination of signalgrass seeds. Seed Science and Technology, 32(2): p. 617-619 (2004).

51. Selim, M. Application of Magnetic Technologies in Correcting Under Ground Brackish Water 
for Irrigation in the Arid and Semi-Arid Ecosystem. in The 3rd Inter. Conf. on Water Resources and Arid Environments, and the 1st Arab water Forum. 2008.

52. Torres, A.D.S., E.P. Leon, and R.C. Fernandez, Efecto del tratamiento magnético de semillas de tomate (Lycopersicon esculentum Mill) sobre la germinación y el crecimiento de las plántulas. Invest. Agr.: Prod. Prot. Veg, 14(3): p. 437-444 (1999).

53. Rochalska, M., Improving of seeds quality with the frequent magnetic field. Part. I. Laboratory experiments. Biuletyn-instytutu Hodowli I Aklimatyzacji Roslin, 2001: p. 6176.

54. Pietruszewski, S., Effects of magnetic biostimulation of wheat seeds on germination, yield and proteins. International agrophysics, 10: p. 51-56 (1996).

55. El-Habbasha, K., A. Shaheen, and F. Rizk, Germination of some tomato cultivars as affected by salinity stress condition. Egyptian Journal of Horticulture (Egypt), 1996.

56. Hilal, M. and M. Hilal, Application of magnetic technologies in desert agriculture. I-Seed germination and seedling emergence of some crops in a saline calcareous soil. Egyptian Journal of Soil Science, 40(3): p. 413-422 (2000).

57. Hajer, A., et al., Responses of three tomato cultivars to sea water salinity 1 . Effect of salinity on the seedling growth. African Journal of Biotechnology, 5(10) (2006).

58. Lin, I.J. and J. Yotvat, Magnetic treatment of water used for agricultural purposes. 1991, Google Patents.

59. Qi, D., et al., Simple approach to wafer-scale self-cleaning antireflective silicon surfaces. Langmuir, 25(14): p. 7769-7772 (2009).

60. Cort, S.L., Methods for removing heavy metals from water using chemical precipitation and field separation methods. 2005, Google Patents.

61. Busch, K.W. and M.A. Busch, Laborator studies on magnetic water treatment and their relationship to a possible mechanism for scale reduction. Desalination, 109(2): $p$. 131-148 (1997).

62. Vermeiren, T.I.S., Magnetic Treatment Device Fob. 1953, Google Patents.

63. Barrett, R.A. and S.A. Parsons, The influence of magnetic fields on calcium carbonate precipitation. Water Research, 32(3): p. 609612 (1998).

64. Min, S., Z.T. Jin, and Q.H. Zhang, Commercial scale pulsed electric field processing of tomato juice. Journal of agricultural and food chemistry, 51(11): p. 3338-3344 (2003).

65. Parsons, S.A., et al., Magnetic treatment of calcium carbonate scale-effect of $\mathrm{pH}$ control. Water Research, 31(2): p. 339-342 (1997).

66. Herzog, R.E., et al., Magnetic water treatment: the effect of iron on calcium carbonate nucleation and growth. Langmuir, 5(3): p. 861-867 (1989).

67. Kronenberg, K., Magnetized II. Aqua Magazine, Sep, (1993). 